\title{
Measuring Dysfunctional Attitudes in the General Population: The Dysfunctional Attitude Scale (form A) Revised
}

\author{
L. Esther de Graaf · Jeffrey Roelofs • \\ Marcus J. H. Huibers
}

Published online: 20 January 2009

(c) The Author(s) 2009. This article is published with open access at Springerlink.com

\begin{abstract}
The Dysfunctional Attitude Scale (DAS) was designed to measure the intensity of dysfunctional attitudes, a hallmark feature of depression. Various exploratory factor analytic studies of the DAS form A (DAS-A) yielded mixed results. The current study was set up to compare the fit of various factor models. We used a large community sample $(N=8,960)$ to test the previously proposed factor models of the DAS-A using confirmatory factor analysis. The retained model of the DAS-A was subjected to reliability and validity analyses. All models showed good fit to the data. Finally, a two-factor solution of the DAS-A was retained, consisting of 17 items. The factors demonstrated good reliability and convergent construct validity. Significant associations were found with depression. Norm-scores were presented. We advocate the use of a 17-item DAS-A, which proved to be useful in measuring dysfunctional beliefs. On the basis of previous psychometric studies, our study provides solid evidence for a two-factor model of the DAS-A, consisting of 'dependency' and 'perfectionism/performance evaluation'.
\end{abstract}

Keywords Dysfunctional attitude scale - Depression . General population - Psychometric analysis .

Factor structure

\section{Introduction}

According to Beck's view of depression (Beck 1972; Beck et al. 1979), individuals vulnerable to depression have

L. E. de Graaf $(\bowtie) \cdot$ J. Roelofs · M. J. H. Huibers

Department of Clinical Psychological Science, Maastricht University, P.O. Box 616, 6200 MD Maastricht, The Netherlands

e-mail: E.deGraaf@dmkep.unimaas.nl maladaptive schemas, which remain dormant until triggered by stressful life events. Dysfunctional beliefs reflect the content of these relatively stable schemas. In the past, many studies were unsuccessful in demonstrating this cognitive vulnerability; dysfunctional beliefs seemed to covary with depressive symptoms, suggesting state dependency rather than vulnerability (for an overview of studies See Ingram et al. 1998). Building on Beck's cognitive model, Teasdale (1988) then suggested that dysfunctional beliefs in vulnerable individuals could only be measured in the presence of a trigger (i.e., a dysphoric mood state). During the first episode of depression, an association between dysfunctional beliefs and depressed mood is created, and dysfunctional beliefs can then be easily activated during a subsequent depressed mood (e.g., Teasdale 1988). Several studies have indeed found support for this 'differential activation hypothesis' using mood priming methods (Ingram et al. 1998; Lau et al. 2004 Miranda et al. 1990).

The measurement of the presence and intensity of dysfunctional beliefs in depression was advanced by the development of the Dysfunctional Attitude Scale (Weissman and Beck 1978). The DAS was originally designed as a measure that would reflect a general cognitive vulnerability factor to depression. However, there is some evidence to suggest that individuals vulnerable to depression may have dysfunctional beliefs only in a few, but not all, areas of their lives (e.g., Dyck 1992; Power et al. 1995, 1994; Sheppard and Teasdale 2000). Moreover, the DAS might be too general to adequately test Beck's cognitive diathesis-stress theory. Beck (1987) later proposed that specific dysfunctional beliefs will interact with particular stressors. Therefore, it is important to focus on specific rather than general dysfunctional beliefs, in research and clinical practice. If the DAS is to be used as a marker of specific vulnerabilities, subscales of the DAS measuring 
specific patterns of maladaptive thinking need to be identified.

Several studies have aimed to investigate the factor structure of the DAS. It is noteworthy to mention that the original form of the DAS, which consists of 100 items, has been refined into two 40-item parallel forms (i.e., DAS-A and DAS-B) by Weissman (1979). Previous research has predominantly relied on the DAS-A. Consequently, most research on the psychometric properties of the DAS has been done with the DAS-A.

The DAS-A has been subjected to exploratory factor analysis by various researchers, which yielded mixed results. Two-factor (e.g., Cane et al. 1986; Imber et al. 1990; Raes et al. 2005; Vaglum and Falkum 1999), threefactor (e.g., Power et al. 1994), and four-factor (e.g., Chioqueta and Stiles 2006; Oliver and Baumgart 1985; Parker et al. 1984) solutions of the DAS-A have been proposed. Moreover, some studies experienced difficulties in determining the number of factors to retain (e.g., Floyd et al. 2004). There are a number of methodological issues that might explain the variability in results from psychometric studies. First, most studies relied on the eigenvalue $>1.0$ or the Scree test to determine the number of factors to retain (e.g., Chioqueta and Stiles 2006; Floyd et al. 2004; Raes et al. 2005; Vaglum and Falkum 1999). These methods have been criticized for being too subjective and possibly leading to an over-extraction of the number of factors (See Zwick and Velicer 1986). Second, the reversely keyed items in the DAS-A might be problematic. In different factor models (i.e., Chioqueta and Stiles 2006; Oliver and Baumgart 1985; Power et al. 1994) these items load on one-factor, possibly representing a 'method' factor rather than a content factor. Third, some studies have included too few individuals to properly conduct exploratory factor analysis (e.g., Floyd et al. 2004; Oliver and Baumgart 1985; Parker et al. 1984; Power et al. 1994; Raes et al. 2005). It has been recommended to have at least 300 cases, and 1,000 cases is regarded as excellent (Comrey and Lee 1992; Field 2000). Regarding confirmatory factor analysis, many fit indices are favorably influenced by having larger sample sizes, desirably more than 200 cases (Marsh et al. 1988, 1998). However, it has been difficult for researchers to determine a rule of thumb regarding the ratio of sample size to number of indicators (e.g., See Meade and Bauer 2007). Despite this variability, there seems to be some consistency with respect to the content of the obtained factors across studies. That is, there are two strong factors representing 'performance or achievement' and '(need for) approval by others'.

Taken together, there is a need for large-scale studies that rely on more stringent methods for examining the psychometric properties of the DAS-A. Confirmatory factor analysis is a more stringent procedure for testing the factor structure of an instrument than exploratory factor analysis, since it relies on a priori information and provides multiple goodness-of fit indices. Therefore, we will subject previously proposed factor models to confirmatory factor analysis with data from a large community sample. To the authors' best knowledge this is the first confirmatory factor analytic investigation of the DAS-A. We will subject the best fitting model of the DAS-A to reliability and validity analyses. We will establish the internal consistency and convergent construct validity. Norm-scores will be assessed and we will explore the extent to which the final model of the DAS-A is associated with depression, controlling for demographic factors. We will use demographic factors that were found to be significant correlates of depression in a large epidemiological community-based study conducted in the Netherlands (NEMESIS, Bijl et al. 1998). In line with other studies (e.g., Blazer et al. 1994; Kessler et al. 1997), they found female sex, middle age (35-44), low educational level, being occupationally disabled or without paid employment, and living without a partner to be associated with depression.

\section{Method}

Participants and Procedure

Data were collected as part of a large-scale screening program to recruit participants for a study, in which the effectiveness of computerized cognitive behavioral therapy for depression will be investigated. A random selection of individuals in the general population (age 18-65) was sent an invitation letter to complete a screening questionnaire via the Internet. Six municipalities in the Southern part of the Netherlands cooperated by providing names and addresses of their residents. The online screening was only accessible by using the unique log-in codes provided in each invitation letter, which could be used just once. This large Internetbased screening was completed by 8,960 (full response rate $8 \%$ ) individuals in the Dutch general population. We compared the demographic variables of our sample and the population in the Southern part of the Netherlands (Statistics Netherlands; www.cbs.nl). No major discrepancies on demographic variables could be detected.

The screening questionnaire consisted of variables concerning depression, dysfunctional attitudes and demographic data. The Medical and Ethical Committee approved the study protocol. Individuals were not compensated for participation.

\section{Measures}

Data collection was cross-sectional and took place via the Internet. All participants completed the Dysfunctional 
Attitude Scale form A, the Diagnostic Inventory for Depression, and completed questions concerning demographic variables (i.e., age, gender, nationality, marital status, education and employment status).

\section{Dysfunctional Attitude Scale form A}

The Dysfunctional Attitude Scale form A (DAS-A) is a self-report scale designed to measure the presence and intensity of dysfunctional attitudes. The DAS-A consists of 40 items and each item consists of a statement and a 7point Likert scale ( $7=$ fully agree; $1=$ fully disagree). Ten items are reversely coded $(2,6,12,17,24,29,30,35$, 37 and 40). The total score is the sum of the 40-items with a range of 40-280. The higher the score, the more dysfunctional attitudes an individual possesses (Weissman and Beck 1978). Internal consistency, test-retest reliability, and average item-total correlations of the DAS-A were satisfactory in different samples (e.g., Cane et al. 1986; Oliver and Baumgart 1985). We used the Dutch version of the DAS-A translated by Raes et al. (2005) which has good psychometric properties.

\section{Diagnostic Inventory for Depression}

The Diagnostic Inventory for Depression (DID) is a 38item self-report scale designed to measure DSM-IV symptom inclusion criteria for a major depressive episode. The DID consists of 19 symptom severity items, 3 symptom frequency items, 8 items measuring interference in daily functioning due to depression, and 8 quality-of-life items. Specified cut-offs to determine the presence or absence of each DSM-IV criterion can be used to diagnose major depressive episode. By adding up the 19 symptom severity items, the severity of depression can be assessed, ranging from 0 (no depression) to 76 (severely depressed) (Sheeran and Zimmerman 2002; Zimmerman et al. 2004). Psychometric properties of the DID are good in terms of internal consistency, test-retest reliability, convergent and discriminant validity, and diagnostic performance (Sheeran and Zimmerman 2002; Zimmerman et al. 2004, 2006).

Using the specified cut-offs of the DID (See Zimmerman et al. 2004), which follow the DSM-IV algorithm, we were able to determine the prevalence of major depressive episode in the current sample.

\section{Analyses}

\section{Confirmatory Factor Analysis}

The robustness of previously published factor models was examined by conducting confirmatory factor analysis by means of LISREL (version 8.54, Jöreskog and Sörbom
1999). First the one-factor model of the DAS-A was tested, followed by the following seven factor models: the twofactor models of Imber et al. (1990, details were provided by Paul A. Pilkonis), Vaglum and Falkum (1999), Cane et al. (1986), and Raes et al. (2005), the three-factor model of Power et al. (1994), and the four-factor models of Chioqueta and Stiles (2006) and Parker et al. (1984). A maximum-likelihood estimation method was adopted. A number of fit indices was used to evaluate the goodness-of fit, including (a) the Root Mean Square Error of Approximation (RMSEA); (b) the Comparative Fit Index (CFI); (c) the Non-Normed Fit Index (NNFI); (d) the Goodness-of Fit Index (GFI); and (e) the Expected Cross-Validation Index (ECVI). Kelloway (1998) indicates that RMSEA values of $<0.10$ represent a good fit, while values below .05 represent a very good fit to the data. Furthermore, a well-fitting model should have CFI, NNFI and GFI values above .90 (values above .95 are indicative of a good to very good fit) (Kelloway 1998). The ECVI is a relative measure to compare competing models; the model with the lowest value has the best fit. However, since the models show a large variability in number of items, it is risky to rely on the ECVI only. Thus, based on all fit indices, the best fitting model was retained in all following analyses.

Since many studies, especially treatment studies, rely on total scores of cognitive measures, we then subjected the one-factor model of the retained DAS-A to confirmatory factor analysis. A likelihood ratio test (LRT), then, was used to compare a more complex model (the retained factor solution) with a simpler model (one-factor solution). The simpler model is a special case of the more complex model (i.e., "nested"). More specifically, under the null-hypothesis that the special model fits as well as the more general one, the difference between their Chi-square-values is itself Chi-square distributed with degrees of freedom equal to the difference between their degrees of freedom.

\section{Reliability, Validity, and Normative Data of the Factors}

SPSS (version 12.0.1 for Windows) was used for all analyses, and the alpha was set to .01 to decrease the likelihood of type I error. Cronbach's alpha and corrected item-total correlations of the factors and of the total score of the retained DAS-A were computed. Convergent construct validity was obtained by computing Pearson correlation coefficient with the severity of depression (DID). The degree to which dysfunctional attitudes could discriminate between depressed and non-depressed individuals was examined by comparing the means of the factors of the retained DAS-A. Normative data were calculated by computing quintiles of the factors as well as for the DAS-A total score. 
Associations of the DAS Factors with Depression Severity

To examine the unique association between dysfunctional attitudes and the severity of depression, multiple linear regression analysis was performed. The outcome variable was the severity of depression as measured with the 19 symptom severity items of the DID. First, scores of the factors of the retained DAS-A were entered in the first step, controlling for demographical variables (gender, age, partner, education and occupational status) in the second step. Second, to determine the unique additional variance of the DAS-A after the variance of demographic variables has been partialled out, these analyses were performed in reverse order (i.e., demographical variables in the first step followed by DAS-A scores in the second step). All variables were standardized prior to the analyses and standardized coefficients were interpreted.

\section{Results}

Sample Characteristics

The sample consisted of 8,960 participants. The sample distribution on socio-demographic variables is shown in Table 1. Individuals were predominantly Caucasian and in the older age groups. The number of females participating was slightly higher than the number of males. The majority had received at least 11 years of education, and was currently employed. Mean DAS-A score was 137.8 ( $\mathrm{SD}=23.6$; range 40-256). The mean DID depression severity score was $8.9(\mathrm{SD}=9.7$; range $0-76)$. According to the specified cut-offs of the DID, $719(8 \%)$ individuals currently suffered from a major depressive episode.

\section{Confirmatory Factor Analysis}

First, we tested the goodness-of-fit of various factor models. Table 2 shows that the results are fairly similar for all tested models. For all models, the RMSEA values were reasonable (all values less than .10 and close to .05). The other indicators were good to very good for all models; NNFI, CFI and GFI were generally well above .90 . Although sufficient, the one-factor model seemed to show the least satisfying fit. Since, the differences in fit between the other models were only marginal, we preferred retaining the most parsimonious model, i.e., a two-factor model. Another reason to retain two factors is that the three- and four-factor models might be the result of overextraction and seemed to contain 'method' factors consisting of reversely keyed items. Inspection of the items in our sample revealed that all ten reversely keyed items showed negative and low item-total correlations (range
Table 1 Demographic characteristics of the sample $(N=8,960)$

\begin{tabular}{|c|c|c|}
\hline Variable & $N$ & $(\%)$ \\
\hline \multicolumn{3}{|l|}{ Gender } \\
\hline Male & 3,965 & $(44.3)$ \\
\hline Female & 4,995 & $(55.7)$ \\
\hline \multicolumn{3}{|l|}{ Age (years) } \\
\hline $18-25$ & 1,052 & $(11.8)$ \\
\hline $26-35$ & 1,276 & $(14.3)$ \\
\hline $36-45$ & 2,148 & $(24.0)$ \\
\hline $46-55$ & 2,682 & $(30.0)$ \\
\hline $56-65$ & 1,795 & $(20.0)$ \\
\hline \multicolumn{3}{|l|}{ Nationality } \\
\hline Dutch & 8,743 & $(97.6)$ \\
\hline Other & 217 & $(2.4)$ \\
\hline \multicolumn{3}{|l|}{ Partner $^{\mathrm{a}}$} \\
\hline Yes & 7,901 & $(89.1)$ \\
\hline No & 969 & $(10.9)$ \\
\hline \multicolumn{3}{|l|}{ Education (in years) ${ }^{\mathrm{b}}$} \\
\hline $0-10$ & 2,519 & $(28.6)$ \\
\hline $11-14$ & 3,067 & $(34.8)$ \\
\hline $15+$ & 3,226 & $(36.6)$ \\
\hline \multicolumn{3}{|l|}{ Occupational status ${ }^{\mathrm{c}}$} \\
\hline Employed & 5,462 & $(64.9)$ \\
\hline Homemaker & 828 & $(9.8)$ \\
\hline Student & 673 & $(8.0)$ \\
\hline Occupational disability/unemployed & 1,063 & $(12.6)$ \\
\hline Retired & 395 & $(4.7)$ \\
\hline
\end{tabular}

${ }^{a}$ Data missing for 90 participants

b Data missing for 148 participants

c Data missing for 539 participants

-.40 to -.13$)$. Although Cronbach's alpha was high for all 40 items (.86), the item-total correlations clearly showed conflicting results. Participants may have answered questions on autopilot. Therefore, we excluded the reversely keyed items in all next steps.

In the next step, we closely inspected the factors and item loadings in the tested models. Two factors have emerged consistently in six of these models (i.e., Cane et al. 1986; Chioqueta and Stiles 2006; Imber et al. 1990; Power et al. 1994; Raes et al. 2005; Vaglum and Falkum 1999): 'perfectionism and performance evaluation' and 'dependency'. For the item selection, the first step was to list the items from these six studies that loaded on either one of these two factors. We only interpreted items with loadings greater than .32 , which is in line with recommendations of Comrey and Lee (1992). In case of double loadings, we accepted the various author's choices regarding which item belonged to which factor. In the final step, we retained 19 items that loaded uniquely on onefactor in at least five of the six studies. Although we 
Table 2 Goodness-of-fit indicators of various factor models of the DAS-A in a large community sample $(N=8,960)$

\begin{tabular}{|c|c|c|c|c|c|}
\hline Model & RMSEA (90\% CI) & ECVI $(90 \%$ CI $)$ & NNFI & $\mathrm{CFI}$ & GFI \\
\hline One-factor model & $.072(0.71-0.72)$ & $3.95(3.88-4.02)$ & .96 & .96 & .84 \\
\hline \multicolumn{6}{|l|}{ Two-factor models } \\
\hline 1. Vaglum and Falkum (1999) & $.069(.068-.071)$ & $1.14(1.10-1.18)$ & .97 & .97 & .91 \\
\hline 2. Imber et al. (1990) & $.073(.072-.074)$ & $1.62(1.57-1.66)$ & .97 & .97 & .89 \\
\hline 3. Cane et al. (1986) & $.066(.065-.067)$ & $1.25(1.21-1.29)$ & .97 & .97 & .91 \\
\hline 4. Raes et al. (2005) & $.062(.061-.062)$ & $1.83(1.78-1.87)$ & .97 & .97 & .90 \\
\hline \multicolumn{6}{|l|}{ Three-factor model } \\
\hline 5. Power et al. (1994) & $.065(.064-.066)$ & $1.28(1.24-1.32)$ & .97 & .97 & .91 \\
\hline \multicolumn{6}{|l|}{ Four-factor models } \\
\hline 6. Parker et al. (1984) & $.067(.066-.068)$ & $1.25(1.21-1.29)$ & .96 & .97 & .91 \\
\hline 7. Chioqueta and Stiles (2006) & $.062(.061-.062)$ & $2.89(2.83-2.95)$ & .97 & .97 & .87 \\
\hline
\end{tabular}

RMSEA root mean square error of approximation; ECVI expected cross-validation index; NNFI non-normed fit index; $C F I$ comparative fit index; GFI goodness-of fit index

Bold indicates the best fit indices

preferred being stringent in deciding which items to retain, we did not select items that loaded on these factors in all models. Due to multiple testing, the chance increases that an item that is expected to belong to a specific factor does not load on that factor in some models.

To test the robustness of this two-factor model, we subjected the 19-item DAS-A to confirmatory factor analysis. The goodness-of-fit indicators were as follows: RMSEA $=0.074 \quad(0.072-0.075), \quad$ ECVI $=0.84 \quad(0.81-$ $0.88), \mathrm{NNFI}=.97, \mathrm{CFI}=0.98$, and GFI $=0.92$. Closer inspection of the results showed that within the first factor items 3 and 4, and items 20 and 21 had residual correlation, indicating that these items have something in common that is not shared with the remaining items of the scale. Because our purpose was to derive the most parsimonious model, we excluded item 3 and item 20 based on their lower factor loadings compared with items 4 and 21 .

In the final step, we subjected the remaining 17 items of the two-factor model of the DAS-A to confirmatory factor analysis. The results were as follows: $\mathrm{RMSEA}=0.065$ (0.063-0.066), ECVI $=0.52(0.49-0.54)$, NNFI $=0.98$, $\mathrm{CFI}=0.98$, and GFI $=0.94$. We also tested the goodnessof fit of the DAS-A-17 as a one-dimensional model. The indicators for the one-factor model were: $\mathrm{RMSEA}=0.097$ (0.095-0.099), ECVI $=1.14(1.10-1.18)$, NNFI $=0.96$, $\mathrm{CFI}=0.96$, and $\mathrm{GFI}=0.88$. Chi-square difference between the one-factor model $\left(\chi^{2}(119)=7,316, p<.001\right)$ and the two-factor model $\left(\chi^{2}(118)=3,987, p<.001\right)$ was $3,329(d f=1, p<.05)$, indicating that the two-factor model fit the data significantly better than the one-factor model. Moreover, the two-factor model had the lowest ECVI value, also indicating a better fit to the data. In Table 3 the items and factor loadings of the retained 17item DAS-A (DAS-A-17) are shown. We labelled the first factor 'perfectionism/performance evaluation'. This factor consisted of 11 items and contained items about perfectionism and concerns about being negatively evaluated by others on the basis of their performance. The second factor, named 'dependency', contained 6 items.

The items were about a need to lean on and be supported by others, and about the dependency of approval and judgments by others in the context of interpersonal relations. ${ }^{1}$

Reliability, Validity, and Normative Data of the Factors

Table 4 depicts Pearson correlation coefficients (corrected for attenuation, i.e., corrected for the reliability coefficient of the instruments) between the DAS-A-17 (factors and total score) and the severity of depression (DID). With respect to the reliability, the correlation between both factors was moderate. In addition, acceptable Cronbach's alpha values were obtained for 'perfectionism/performance evaluation', 'dependency', and the DAS-A-17 total score, respectively $.90, .81$ and .91 . The mean corrected item-total correlations were sufficient, .64 (range .51 to .77) and .58 (range .44 to .66) respectively, for 'perfectionism/performance evaluation' and 'dependency'.

Regarding the convergent construct validity, 'perfectionism/performance evaluation' factor and the DAS-A-17

\footnotetext{
1 An anonymous reviewer suggested that the factor structure of the DAS-A might differ in depressed and non-depressed individuals. We therefore subjected the two-factor model of the DAS-A-17 to confirmatory factor analysis in a depressed and non-depressed subgroup separately. Depression status was based on the criteria of the DID. The results are fairly similar in both subgroups. The results for the depressed subgroup $(N=719)$ were as follows: RMSEA $=.054(.048-.060), \mathrm{ECVI}=0.61(0.53-0.69), \mathrm{NNFI}=.99$, $\mathrm{CFI}=.99$, and $\mathrm{GFI}=.94$. For the non-depressed subgroup $(N=8241)$ the results were: RMSEA $=.065(.063-.066)$, ECVI $=$ $0.51(0.49-0.54), \mathrm{NNFI}=.97, \mathrm{CFI}=.98$, and $\mathrm{GFI}=.94$.
} 
Table 3 Item descriptions and their factor loadings of the DAS-A-17

\begin{tabular}{ll}
\hline Item & Item description \\
\hline Perfectionism/performance evaluation \\
1. & It is difficult to be happy, unless one is good looking, intelligent, rich and creative. \\
4. & If I do not do well all the time, people will not respect me. \\
8. & If a person asks for help, it is a sign of weakness. \\
9. & If I do not do as well as other people, it means I am an inferior human being. \\
10. & If I fail at my work, then I am a failure as a person. \\
11. & If you cannot do something well, there is little point in doing it at all. \\
13. & If someone disagrees with me, it probably indicates that he does not like me. \\
14. & If I fail partly, it is as bad as a complete failure. \\
15. & If other people know what you're really like, they will think less of you. \\
21. & If I am to be a worthwhile person, I must be truly outstanding in at least one major respect. \\
26. & If I ask a question, it makes me look inferior. \\
Dependency & \\
19. & My value as a person depends greatly on what others think of me. \\
27. & It is awful to be disapproved of by people important to you. \\
28. & If you don't have other people to lean on, you are bound to be sad. \\
32. & If others dislike you, you cannot be happy. \\
34. & My happiness depends more on other people than it does on me. \\
38. & What other people think about me is very important. \\
\hline
\end{tabular}

$D A S-A-17$ dysfunctional attitude scale with 17 items

Table 4 Correlation matrix of dysfunctional attitudes and depression severity $(N=8,960)$

\begin{tabular}{lllll}
\hline Scale & 1 & 2 & 3 & 4 \\
\hline DID & - & .61 & .51 & .60 \\
DAS-A-17-P & & - & .79 & .95 \\
DAS-A-17-D & & & - & .87 \\
DAS-A-17-T & & & & - \\
\hline
\end{tabular}

$D A S-A-17$ dysfunctional attitude scale with 17 items, $P$ perfectionism/ performance evaluation, $D$ dependency, $T$ total score; $D I D$ total score of the 19 symptom severity items of the diagnostic inventory for depression

Correlations are corrected for attenuation (i.e., corrected for reliability coefficient of the scales)

total score were more strongly correlated with depression severity compared with 'dependency' ( $p s<.001$; See Table 4). Furthermore, Table 5 shows that the depressed subgroup scored significantly higher on both factors and on the total score than the non-depressed individuals.

Finally, Table 6 presents normative data of the DAS-A17 factors and total score.

Associations of Dysfunctional Attitudes With Depression Severity

Results of the multiple linear regression analysis are summarized in Table 7. The results show that the 'perfectionism/performance evaluation' and 'dependency'
Table 5 Means and standard deviations of the DAS-A-17 factors and total score for the non-depressed $(N=8,241)$ and depressed $(N=719)$ subgroups

\begin{tabular}{lllllrl}
\hline & \multicolumn{2}{l}{ Non-depressed } & & \multicolumn{2}{l}{ Depressed } & \multirow{2}{*}{$t(d f)$} \\
\cline { 2 - 3 } & $M$ & SD & & $M$ & SD & \\
\hline DAS-A-17-P & 26.3 & 9.6 & & 41.1 & 13.1 & $-29.6(787)^{*}$ \\
DAS-A-17-D & 20.0 & 6.6 & & 27.0 & 7.1 & $-25.5(829)^{*}$ \\
DAS-A-17-T & 46.3 & 14.7 & & 68.1 & 18.5 & $-30.7(799)^{*}$ \\
\hline
\end{tabular}

$D A S-A-17$ dysfunctional attitude scale with 17 items, $P$ perfectionism/ performance evaluation, $D$ dependency, $T$ total score

$* p<.001$

together account for $31 \%$ of the total variance in depression severity $(F(2)=1,863.7, p<.001)$. 'Perfectionism/performance evaluation' was significantly and substantially associated with depression. After controlling for demographic variables in the second step $(F(14)=375.9$, $p<.001$ ), this factor remained to have the strongest association with depression. In contrast, the association between 'dependency' and depression was much smaller. It should be noticed that when demographic variables were added to the model in the second step, unemployment/ occupational disability appeared more strongly associated with depression than 'dependency'.

To determine the unique additional variance of the DAS-A-17 after the variance of demographic variables has been partialled out, we repeated these analyses in reverse 
Table 6 Norm-scores for the DAS-A-17 factors and total score $(N=8,960)$

\begin{tabular}{lllll}
\hline Quintile & Standardization & $\begin{array}{l}\text { DAS-A- } \\
17-\mathrm{P}\end{array}$ & $\begin{array}{l}\text { DAS-A- } \\
17-\mathrm{D}\end{array}$ & $\begin{array}{l}\text { DAS-A- } \\
17-\mathrm{T}\end{array}$ \\
\hline 1 & Low & 19 & 15 & 35 \\
2 & Below average & & & \\
3 & Average & 23 & 18 & 42 \\
4 & Above average & 27 & 22 & 49 \\
& & 35 & 27 & 60 \\
\hline
\end{tabular}

Normative data were calculated by computing quintiles; $D A S-A-17$ dysfunctional attitude scale with 17 items, $P$ perfectionism/performance evaluation, $D$ dependency, $T$ total score

Table 7 Multiple linear regression analysis with depression severity as outcome variable: associations with dysfunctional attitudes and demographic variables $(N=8,960)$

\begin{tabular}{|c|c|c|c|}
\hline Variable & $B$ & $\mathrm{SE}(B)$ & $\beta$ \\
\hline \multicolumn{4}{|l|}{ Step 1} \\
\hline DAS-A-17-P & .464 & .012 & $.472 *$ \\
\hline DAS-A-17-D & .119 & .012 & $.121^{*}$ \\
\hline \multicolumn{4}{|l|}{ Step 2} \\
\hline DAS-A-17-P & .405 & .012 & $.412^{*}$ \\
\hline DAS-A-17-D & .129 & .012 & $.131^{*}$ \\
\hline Gender, female & .041 & .009 & $.042 *$ \\
\hline \multicolumn{4}{|l|}{ Age (compared to $18-25)$} \\
\hline $26-35$ & .002 & .015 & .002 \\
\hline $36-45$ & .012 & .018 & .012 \\
\hline $46-55$ & -.008 & .019 & -.008 \\
\hline $56-65$ & -.091 & .018 & $-.092 *$ \\
\hline Partner, yes & -.039 & .009 & $-.039 *$ \\
\hline \multicolumn{4}{|l|}{ Education in years (compared to $0-10$ ) } \\
\hline $11-14$ & -.043 & .010 & $-.043^{*}$ \\
\hline $15+$ & -.086 & .011 & $-.088 *$ \\
\hline \multicolumn{4}{|l|}{ Occupational status (compared to employed) } \\
\hline Homemaker & .017 & .009 & .018 \\
\hline Student & -.016 & .013 & -.016 \\
\hline Occupational disability/unemployed & .246 & .009 & $.251^{*}$ \\
\hline Retired & -.008 & .010 & -.008 \\
\hline
\end{tabular}

$R^{2} .31$ for step $1 ; \Delta R^{2} .08$ for step $2(p \mathrm{~s}<.001)$

Outcome variable is the severity of depression as measured with the 19 symptom severity items of the diagnostic inventory for depression

$D A S-A-17$ dysfunctional attitude scale with 17 items, $P$ perfectionism/ performance evaluation, $D$ dependency

$* p<.001$

order. In the first step, demographic variables explained $15 \%$ of the total variance in depression $(F(12)=115.8$, $p<.001)$. By adding both factors of the DAS-A-17 to the model an extra $25 \%$ of the total variance could be explained $(F(14)=375.9, \quad p<.001)$. Thus, in both regression analyses, the DAS-A-17 factors explained a substantial and significant proportion of the variance in depression.

Since it has generally been argued that 'dependency' is mainly salient in women and 'perfectionism/performance evaluation' is more often exhibited by men (Beck 1983), gender differences might be present. Therefore, ancillary analyses were performed. First, we compared the mean scores on both factors by performing independent samples $t$-tests. Both factor scores were significantly higher in women than in men $(p s<.05)$. Second, we conducted regression analyses to test interaction effects between gender and both DAS-A-17 factors as predictors of depression. The full model (i.e., demographic variables and both factors) was entered in the first step, followed by two interaction terms (i.e., gender $\times$ 'perfectionism/performance evaluation', and gender $x$ 'dependency') in the second step. The interactions were non-significant ( $p$ values well above .05).

\section{Discussion}

\section{Main Findings}

The present study sought to examine the psychometric properties of the DAS-A in a large community sample $(N=8,960)$. Specifically, we were able to conduct confirmatory factor analysis, which provides a methodological advance in factor analysis. We compared the fit of seven competing models of the factor structure of the DAS-A. Since all models had a good fit, we retained the most parsimonious model. Seventeen items of the original 40item DAS-A were retained and comprised a two-factor solution: 'perfectionism/performance evaluation' and 'dependency'. Confirmatory factor analysis indicated that this two-factor solution produced good fit to the data based on several goodness-of-fit indicators. Psychometric properties of the obtained factors were sufficient, in terms of internal consistency, item-total correlations and convergent construct validity. Both factors were significantly associated with depression, controlling for demographic variables. Surprisingly, the association between 'dependency' and depression was relatively small.

\section{Previous Factor Analytic Studies}

One of the aims of the current study was to discern meaningful subscales of the DAS-A, which can be used as measures of specific cognitive vulnerabilities in order to more adequately test the cognitive diathesis-stress theory 
of Beck (1972). Therefore, we have tested several previously suggested models of the DAS-A (i.e., Cane et al. 1986; Chioqueta and Stiles 2006; Imber et al. 1990; Parker et al. 1984; Power et al. 1994; Raes et al. 2005; Vaglum and Falkum 1999). Although, all tested models had a good fit, we suggest adopting a two-factor solution for several reasons. First, two factors (i.e., 'performance or achievement' and '(need for) approval by others') have emerged across different populations in earlier studies. Second, these two factors were most interpretable and are theoretically meaningful; they have been suggested as appropriate specific dimensions of dysfunctional attitudes (Beck 1983). Finally, factors in three- and four-factor solutions (i.e., Chioqueta and Stiles 2006; Oliver and Baumgart 1985; Parker et al. 1984; Power et al. 1994) were more difficult to interpret, and they might be the result of over-extraction due to methodological shortcomings.

While most studies focused on the psychometric properties of the DAS-A, others have examined the structure of the full 100-item DAS and the DAS-B (e.g., See Beck et al. 1991; Power et al. 1994). The authors of these two studies have both found other important factors next to 'perfectionism/performance evaluation' and 'dependency'. First, a factor labeled 'self-control' was found in the DAS-B, but did not appear in the DAS-A (Power et al. 1994). To date, 'self-control' has received relatively little attention in research on cognitive vulnerability of depression. It might be interesting for future research to elaborate more on this. Second, Beck et al. (1991) have found a general symptom factor, named 'vulnerability', reflecting a general negative view of the world. However, this factor seemed rather state dependent as compared with the 'need for approval' and 'perfectionism' factors. When specifically interested in vulnerability of depression, one might prefer to use more stable factors.

\section{Reliability}

A few comments should be made regarding the reliability of the obtained factors of the DAS-A-17. First, both factors appear to be reliable measures of specific constructs of dysfunctional attitudes. However, comparable to previous findings (e.g., Cane et al. 1986; Imber et al. 1990) the internal consistency is relatively smaller for 'dependency' than for 'perfectionism/performance evaluation'. The smaller number of items in the 'dependency' factor might explain this. The number of items on a scale influences Cronbach's alpha; when the number of items decreases Cronbach's alpha decreases. However, item-total correlations were also relatively smaller for 'dependency' than for 'performance evaluation'. This may suggest that dependency is a rather heterogeneous factor and may still be too broad (e.g., Mazure et al. 2001).
Second, since total scores are often used in research and in clinical practice, the reliability of the total score of the DAS-A-17 was examined and appeared satisfactory. As the inter-correlation between both factors of the DAS-A-17 was moderate, it can even be argued that the DAS-A should preferably be used as a one-dimensional measure of dysfunctional attitudes. Moreover, the results of the confirmatory factor analysis showed that the one-factor model, of both the 40-item and 17-item DAS-A, fit the data sufficiently. Therefore, it seems justified to use the DAS-A as a one-dimensional construct. The total score might reflect a higher order construct measuring dysfunctional thinking in general. Still, the two-factor solution produced better fit to the data than the one-factor solution of the DAS-A-17.

Third, a point should be made regarding the reversely keyed items. Although usually used to prevent response tendencies, the present results suggest that reversely keyed items endorse contradictory statements. Sahin and Sahin (1992) expressed their concerns about the reversely keyed items of the DAS-A as well. In a student sample, they found that the reversely keyed items of the DAS-A formed a factor. The same problem may have emerged in previous factor analytic studies (e.g., Chioqueta and Stiles 2006; Oliver and Baumgart 1985; Power et al. 1994). Since participants had difficulties grasping the concept of these reversely keyed items, we decided to omit those items from the DAS-A. However, if the use of reversely keyed items is preferred in a questionnaire, one could elaborate the instructions for the reader and draw the participant's attention to negatively and positively stated items.

\section{Validity}

Regarding the validity, both factors showed sufficient convergent construct validity and could distinguish the depressed subgroup from the non-depressed group. Depression was significantly explained by both factors, controlling for demographic determinants of depression (See Bijl et al. 1998). The content of the obtained factors of the DAS-A-17 largely resemble two specific dimensions of cognitive vulnerability to depression: sociotropy and autonomy (Beck 1983). Whereas sociotropy refers to a need for intimacy, affiliation and dependency, autonomy refers to as a need for goal achievement and fear of failure (Beck 1983). Previous studies generally found stronger indications for sociotropy as risk factor to depression compared with autonomy. The present results suggest the opposite. Methodological differences may in part explain these contrasting results. First, we used a cross-sectional design, which makes it difficult to distinguish vulnerability from its manifestation in depression. 'Perfectionism/performance evaluation' may covary more closely with symptom state than 'dependency' (Beck et al. 1991; Coyne 
and Whiffen 1995). This is supported by the high correlation we found between 'perfectionism/performance evaluation' and depression severity. Second, poor scale reliability can attenuate the correlation between two variables. Since the alpha of the 'dependency' factor was relatively lower than for 'perfectionism/performance evaluation', this might explain its lower correlation with depression. However, we corrected for this attenuationeffect. Third, previous studies relied on other instruments to measure autonomy and sociotropy, which may differ from the DAS-A in terms of their contents (e.g., See Pincus and Gurtman 1995). It might be interesting to directly compare the two factors of the DAS-A-17 with the scales of the Sociotropy-Autonomy Scale. This might further support its validity. Finally, a possible explanation would have been that gender interacted with the obtained factors. It has been argued that sociotropy mainly acts as a vulnerability factor in women and autonomy in men (Beck 1983). Some studies indeed found an interaction effect for gender and sociotropy on depression, but not for autonomy (e.g., Sato and McCann 1998; Shih 2006). Although our findings suggest that there are gender differences in mean scores on both factors, the association between both factors of the DAS-A-17 and depression did not differ significantly as a function of gender. We need further research, since only few studies have examined the role of gender differences.

\section{Methodological Limitations}

Several limitations of the present study should be noted. First, a potential problem in the use of online data collection is that of providing false (demographic) information and that of multiple submissions. However, our sampling method (i.e., written invitations with unique log-in codes) made it possible to more reliably identify the population. Second, our full response rate was very low (8\%). Since no major discrepancies on demographic variables arose between our sample and the population in the Southern part of the Netherlands (Statistics Netherlands; www.cbs.nl), this might not be a reason for concern. However, as in most previous psychometric studies of the DAS-A, predominantly Caucasian individuals were assessed. The usefulness of the DAS-A(-17) and its factors needs to be investigated in samples representing different demographic and cultural backgrounds. Third, because of the cross-sectional nature of the study we were not able to investigate the predictive value of the obtained factors of the DAS-A. Consequently, the present study is lacking validity research. To address this issue, experimental or longitudinal designs are needed rather than cross-sectional designs. Fourth, the generalizibility of the present findings might be limited due to our recruitment method. Only individuals with access to the
Internet were able to participate. In line with this, one may question the equality of computerized questionnaires and paper-and-pen versions. However, there are sufficient indications that computerized and paper-and-pen questionnaires show similar construct validity (Butcher et al. $2000,2004)$. However, when a questionnaire is placed on the Internet this might subtly affect expected score distributions, perhaps due to increased self-disclosure or increased negative affect induced by the computer situation (Buchanan 2003; Peterson et al. 1996). The normative data presented here might not be appropriate for the offline version of the DAS-A-17. Fifth, we relied on self-report measures and did not use a diagnostic interview. Information on past episodes of depression and other disorders, such as dysthymia, is lacking. Sixth, we used a rather heterogeneous community sample and one might question whether the factor structure of the DAS-A is similar in depressed and non-depressed individuals. However, we showed that the fit of the two-factor solution was fairly similar in a depressed and non-depressed subgroup. We think that dysfunctional attitudes can best be conceptualized as reflecting quantitative rather than qualitative differences among individuals (See also Gibb et al. 2004). Moreover, we were able to find a good fit despite the variability in depression status. Finally, in our proposed factor model we selected nineteen items that loaded on two common factors in at least five of six studies. Although this was carefully considered, we admit this is as a somewhat arbitrary choice. Nevertheless, we believe this is a fair approach to derive two meaningful and uniform factors.

\section{Conclusion}

In conclusion, we advocate the use of a 17-item DAS-A, which proved to be useful in defining and measuring dysfunctional beliefs in the general population. Although the 40-item DAS-A has good psychometric properties, the DAS-A-17 has several advantages over the full version. The DAS-A-17 consists of two theoretically meaningful subscales, which can be of great use in future research on cognitive vulnerability factors in depression. Furthermore, we have demonstrated that the DAS-A-17 possesses good psychometric properties in terms of model fit, reliability, and convergent construct validity. And finally, for practical reasons, many researchers and clinicians might favour a shortened version. The 17-item version can shorten administration time, while its psychometric quality is maintained. Thus, together with results from previous psychometric studies, our study provides a solid evidencebase for a specific two-factor structure of the DAS-A across settings and populations, consisting of 'dependency' and 'perfectionism/performance evaluation'. 
Acknowledgments We thank Annie Hendriks, Greet Kellens, and Sylvia Gerhards, who assisted with data collection. Rosanne Janssen developed the infrastructure for online data collection. Municipalities Eijsden, Meerssen, Sittard-Geleen, Valkenburg, and Maastricht sponsored the study.

Open Access This article is distributed under the terms of the Creative Commons Attribution Noncommercial License which permits any noncommercial use, distribution, and reproduction in any medium, provided the original author(s) and source are credited.

\section{References}

Beck, A. T. (1972). Depression: Causes and treatment. Philadelphia: University of Pennsylvania Press.

Beck, A. T. (1983). Cognitive therapy of depression: New perspectives. In P. J. Clayton \& J. E. Barrett (Eds.), Treatment of depression: Old controversies and new approaches (pp. 265290). New York: Raven Press.

Beck, A. T. (1987). Cognitive models of depression. Journal of Cognitive Psychotherapy: An International Quarterly, 1, 5-37.

Beck, A. T., Brown, G., Steer, R. A., \& Weissman, A. N. (1991). Factor analysis of the dysfunctional attitude scale in a clinical population. Psychological Assessment, 3(478), 183. doi: 10.1037/1040-3590.3.3.478.

Beck, A. T., Rush, A. J., Shaw, B. F., \& Emery, G. (1979). Cognitive therapy of depression. New York: Guildford Press.

Bijl, R. V., Ravelli, A., \& van Zessen, G. (1998). Prevalence of psychiatric disorder in the general population: Results of the Netherlands mental health survey and incidence study (NEMESIS). Social Psychiatry and Psychiatric Epidemiology, 33, 587595. doi:10.1007/s001270050098.

Blazer, D. G., Kessler, R. C., McGonagle, K. A., \& Swartz, M. S. (1994). The prevalence and distribution of major depression in a national community sample: The National comorbidity survey. The American Journal of Psychiatry, 151, 979-986.

Buchanan, T. (2003). Internet-based questionnaire assessment: Appropriate use in clinical contexts. Cognitive Behaviour Therapy, 32, 100-109. doi:10.1080/16506070310000957.

Butcher, J. N., Perry, J. N., \& Atlis, M. M. (2000). Validity and utility of computer-based test interpretation. Psychological Assessment, 12, 6-18. doi:10.1037/1040-3590.12.1.6.

Butcher, J. N., Perry, J., \& Hahn, J. (2004). Computers in clinical assessment: Historical developments, present status, and future challenges. Journal of Clinical Psychology, 60, 331-345. doi: 10.1002/jclp.10267.

Cane, D. B., Olinger, J., Gotlib, I. H., \& Kuiper, N. A. (1986). Factor structure of the dysfunctional attitude scale in a student population. Journal of Clinical Psychology, 42, 307-309. doi: 10.1002/1097-4679(198603)42:2\&1t;307::AIDJCLP2270420213\&gt;3.0.CO;2-J.

Chioqueta, A. P., \& Stiles, T. C. (2006). Factor structure of the dysfunctional attitude scale (Form A) and the automatic thoughts questionnaire: An exploratory study. Psychological Reports, 99, 239-247. doi:10.2466/PR0.99.5.239-247.

Comrey, A. L., \& Lee, H. B. (1992). A first course in factor analysis (2nd ed.). Hillsdale, NJ: Erlbaum.

Coyne, J. C., \& Whiffen, V. E. (1995). Issues in personality as diathesis for depression: The case of sociotropy-dependency and autonomy-self-criticism. Psychological Bulletin, 118, 358-378. doi:10.1037/0033-2909.118.3.358.

Dyck, M. J. (1992). Subscales of the dysfunctional attitude scale. The British Journal of Clinical Psychology, 31, 333-335.
Field, A. (2000). Discovering statistics using SPSS for Windows. London: Sage.

Floyd, M., Scogin, F., \& Chaplin, W. F. (2004). The dysfunctional attitude scale: Factor structure, reliability and validity with older adults. Aging \& Mental Health, 8, 153-160. doi:10.1080/136078 60410001649572.

Gibb, B. E., Alloy, L. B., Abramson, L. Y., Beevers, C. G., \& Miller, I. W. (2004). Cognitive vulnerability to depression: A taxometric analysis. Journal of Abnormal Psychology, 113, 81-89. doi: 10.1037/0021-843X.113.1.81.

Imber, S. D., Pilkonis, P. A., Sotsky, S. M., Elkin, I., Watkins, J. T., Collins, J. F., et al. (1990). Mode-specific effects among three treatments for depression. Journal of Consulting and Clinical Psychology, 58, 352-359. doi:10.1037/0022-006X.58.3.352.

Ingram, R. E., Miranda, J., \& Segal, Z. V. (1998). Cognitive vulnerability to depression. New York: Guilford Press.

Jöreskog, K. G., \& Sörbom, D. (1999). LISREL 8.30. Chicago, IL: Scientific software International.

Kelloway, E. K. (1998). Using LISREL for structural equation modeling: A researcher's guide. Thousand Oaks, CA: Sage.

Kessler, R. C., Zhao, S., Blazer, D. G., \& Swartz, M. (1997). Prevalence, correlates, and course of minor depression and major depression in the national comorbidity survey. Journal of Affective Disorders, 45, 19-30. doi:10.1016/S0165-0327(97) 00056-6.

Lau, M. A., Segal, Z. V., \& Williams, J. M. G. (2004). Teasdale's differential activation hypothesis: implications for mechanisms of depressive relapse and suicidal behaviour. Behaviour Research and Therapy, 42, 1001-1017. doi:10.1016/j.brat.2004. 03.003 .

Marsh, H. W., Balla, J. R., \& McDonals, R. P. (1988). Goodness-of-fit indexes in confirmatory factor analysis: The effect of sample size. Psychological Bulletin, 103, 391-410. doi:10.1037/00332909.103.3.391.

Marsh, H. W., Hau, K. T., Balla, J. R., \& Grayson, D. (1998). Is more ever too much? The number of indicators per factor in confirmatory factor analysis. Multivariate Behavioral Research, 33, 181-220. doi:10.1207/s15327906mbr3302_1.

Mazure, C. M., Raghaven, C., Maciejewski, P. K., Jacobs, S. C., \& Bruce, M. L. (2001). Cognitive-personality characteristics as direct predictors of unipolar major depression. Cognitive Therapy and Research, 25, 215-225. doi:10.1023/A:1026424126287.

Meade, A. W., \& Bauer, D. J. (2007). Power and precision in confirmatory factor analytic tests of measurement invariance. Structural Equation Modeling: A Multidisciplinary Journal, 14, 611-635.

Miranda, J., Persons, J. B., \& Byers, C. N. (1990). Endorsement of dysfunctional beliefs depends on current mood state. Journal of Abnormal Psychology, 99, 237-241. doi:10.1037/0021-843X. 99.3.237.

Oliver, J. M., \& Baumgart, E. P. (1985). The dysfunctional attitude scale: Psychometric properties and relation to depression in an unselected adult population. Cognitive Therapy and Research, 9, 161-167. doi:10.1007/BF01204847.

Parker, G., Bradshaw, G., \& Blignault, I. (1984). Dysfunctional attitudes: Measurement, significant constructs and links with depression. Acta Psychiatrica Scandinavica, 70, 90-96. doi:10.1111/ j.1600-0447.1984.tb01186.x.

Peterson, L., Johansson, V., \& Carlsson, S. G. (1996). Computerised testing in a hospital setting: Psychometric and psychological effects. Computers in Human Behavior, 12, 339-350. doi: 10.1016/0747-5632(96)00012-X.

Pincus, A. L., \& Gurtman, M. B. (1995). The three faces of interpersonal dependency: Structural analyses of self-report dependency measures. Journal of Personality and Social Psychology, 69, 744-758. doi:10.1037/0022-3514.69.4.744. 
Power, M. J., Duggan, C. F., Lee, A. S., \& Murrey, R. M. (1995). Dysfunctional attitudes in depressed and recovered depressed patients and their first-degree relatives. Psychological Medicine, 25, 87-93.

Power, M. J., Katz, R., McGuffin, P., Duggan, C. F., Lam, D., \& Beck, A. T. (1994). The dysfunctional attitude scale (DAS) a comparison of forms A and B and proposals for a new subscaled version. Journal of Research in Personality, 28, 263-276. doi: 10.1006/jrpe.1994.1019.

Raes, F., Hermans, D., Van den Broeck, K., \& Eelen, P. (2005). Kort Instrumenteel: De Nederlandstalige versie van de Dysfunctional Attitude Scale-vorm A (DAS-A-NL). Gedragstherapie, 38, 285294. The Dutch version of the Dysfunctional Attitude Scale-form A (DAS-A-NL).

Sahin, N. H., \& Sahin, N. (1992). How dysfunctional are the dysfunctional attitudes in another culture? The British Journal of Medical Psychology, 65, 17-26.

Sato, T., \& McCann, D. (1998). Individual differences in relatedness and individuality: An exploration of two constructs. Personality and Individual Differences, 24, 847-859. doi:10.1016/S01918869(98)00020-8.

Sheeran, T., \& Zimmerman, M. (2002). Case identification of depression with self-report questionnaires. Psychiatry Research, 109, 51-59. doi:10.1016/S0165-1781(01)00364-X.

Sheppard, L. C., \& Teasdale, J. D. (2000). Dysfunctional thinking in major depressive disorder: A deficit in metacognitive monitoring. Journal of Abnormal Psychology, 109, 768-776. doi:10.1037/ 0021-843X.109.4.768.

Shih, J. H. (2006). Sex differences in stress generation: An examination of sociotropy/autonomy, stress, and depressive symptoms. Personality and Social Psychology Bulletin, 32, 434-446. doi:10.1177/0146167205282739.

Teasdale, J. D. (1988). Cognitive vulnerability to persistent depression. Cognition and Emotion, 2, 247-274. doi:10.1080/ 02699938808410927.

Vaglum, P., \& Falkum, E. (1999). Self-criticism, dependency and depressive symptoms in a nationwide sample of Norwegian physicians. Journal of Affective Disorders, 52, 153-159. doi: 10.1016/S0165-0327(98)00081-0.

Weissman, A.N. (1979). Assessing depressogenic attitudes: A validation study. Unpublished thesis, University of Pennsylvania.

Weissman, A.N., \& Beck, A.T.(1978). Development and validation of the dysfunctional attitude scale. Paper presented at the Annual meeting of the Association for the Advanced Behavior Therapy, Chicago, November.

Zimmerman, M., Chelminski, I., McGlinchey, J. B., \& Young, D. (2006). Diagnosing major depressive disorder VI; performance of an objective test as a diagnostic criterion. The Journal of Nervous and Mental Disease, 194, 565-569. doi:10.1097/ 01.nmd.0000230393.19478.d5.

Zimmerman, M., Sheeran, T., \& Young, D. (2004). The diagnostic inventory for depression: A self-report scale to diagnose DSMIV major depressive disorder. Clinical Psychologist, 60, 87-110. doi:10.1002/jclp.10207.

Zwick, W. R., \& Velicer, W. F. (1986). Comparison of five rules for determining the number of components to retain. Psychological Bulletin, 99, 432-442. doi:10.1037/0033-2909.99.3.432. 